\title{
Instituciones Normalizadoras para Anormales
}

\author{
Elsa Georgina Aponte Sierra \\ Universidad Pedagógica y Tecnológica de Colombia - Colombia
}

Autor de correspondencia: 1'elsa.aponte@uptc.edu.co

Recibido: 30 de septiembre de 2019 Revisado: 05 de diciembre de 2019 Aprobado: 28 de marzo de 2020 Publicado: 23 de junio de 2020

\section{Resumen}

El artículo presenta una mirada a las instituciones como parte de la constitución de sujetos anormales, fundamentada de la investigación: Educación de Anormales: perspectivas educativas y pedagógicas en Colombia. Se ubica en los años 40 a 70 del siglo XX, momento histórico que revela el proceso de modernización, donde los organismos internacionales como: UNESCO, OEA, ONU, UNICEF, están interesados en intervenir los países subdesarrollados, el gobierno colombiano manifiesta su complacencia efectuando alianzas de poder para diseñar estrategias que puedan proyectar la producción nacional, reconociendo el uso de la tecnología y la preparación del capital humano, como medios para gestión de la población. El estudio realizado es de tipo arqueológico-genealógico, el cual está centrado por un lado en la erudición, es decir, el conocimiento amplio y vasto de los acontecimientos y por otro lado en un trabajo minucioso, paciente que intenta recopilar documentos y desde allí ir encontrando pequeñas verdades o interpretaciones aparentemente sin importancia que configuran y crean realidad.

Palabras clave: biopolítica, instituciones, anormales, educación.

\section{(9) $(\Theta \Theta \Theta$}




\title{
Normalizing institutions for abnormals
}

\begin{abstract}
The article presents a review of institutions role as part of the constitution of abnormal subjects, based in the research: Education of Abnormal: educational and pedagogical perspectives in Colombia. This study, was focus in the 40s to 70s of the 20th century, a historic moment that reveals the modernization process, where international organizations such as: UNESCO, OAS, UN, UNICEF, were interest in intervening on underdeveloped countries, in consequience, the colombian goverment showed its complacency making Power alliances to design strategies that could project national production, recognizing the use of technology and the preparation of human capital, as means for population management .. The investigation is of an archaeological-genealogic type, is focused, on the one hand, in the erudition, that is, the deep knowledge of facts, and the other hand, in an itemized work that tries to collect documents, and trough of your analysis, find small truths or apparently insignificant interpretations that configure and create reality.
\end{abstract}

Keywords: biopolitics, institutions, abnormals, education

\section{Instituições de Normalização pra anormais}

\section{Resumo}

O artigo apresenta um olhar sobre as instituições como parte da constituição de sujeitos anormais, com base na pesquisa: Educação anormal: perspectivas educacionais e pedagógicas na Colômbia. Educação anormal: perspectivas educacionais e pedagógicas na Colômbia. Está localizado nas décadas de 40 a 70 do século $\mathrm{XX}$, momento histórico que revela o processo de modernização, onde organizações internacionais como: UNESCO, OEA, ONU, UNICEF estejam interessadas em intervir em países subdesenvolvidos, o governo colombiano expressa sua satisfação ao fazer alianças de poder para elaborar estratégias que possam projetar a produção nacional, reconhecendo o uso da tecnologia e a preparação do capital humano, como forma de gerenciar a população. O estudo realizado é do tipo arqueológico-genealógico, que se concentra, por um lado, na erudição, ou seja, o amplo e vasto conhecimento dos eventos e, por outro lado, num trabalho meticuloso, paciente que tenta coletar documentos e de lá encontrar pequenas verdades ou interpretações aparentemente insignificantes que configuram e criam a realidade.

Palavras chave: biopolítica, instituições, anormais, educação.

\section{Introducción}

En los años comprendidos entre la década de los 40 a 70 del siglo XX, se consolidan formas de organizar la vida de los colombianos: la higienización y la educalización, dos estrategias biopolíticas que se llevan a la práctica por medio de normas, leyes, guías pedagógicas, programas de alfabetización, la planeación educativa por niveles, el seguimiento, 
control médico, que debe tener como resultado el control de la vida de los ciudadanos, el bienestar del cuerpo y por lo tanto la disponibilidad de la fuerza de trabajo. Esta situación se presentaba en medio de enfrentamientos políticos bipartidistas y altos niveles de violencia, que, sin embargo, no frenaron la intención de expansión de la educación, la planificación, los diagnósticos; se mantuvieron igualmente los discursos sobre lo que significa modernizar a la población.

Esta mirada no lineal sobre la educación-institucionalización se ubica en el marco de los estudios sociales y culturales en torno a la modernidad/colonialidad en Colombia, desarrollados por un grupo de filósofos, sociólogos y antropólogos, liderados por Santiago Castro-Gómez' (Castro-Gómez, 2007; Castro-Gómez \& Grosfoguel, 2007; Castro-Gómez \& Restrepo, 2008), que invitan a revisar de qué forma nos hemos constituido como sujetos pertenecientes a un mundo capitalista. En el momento histórico señalado no solo se educa en torno a una verdad evolucionista, sino que nos señala como una cultura que pertenece al sistema/mundo y que su orden, también le daría al país un lugar en las escalas de desarrollo según el cumplimiento de ciertos requisitos para ser un país considerado moderno, así lo menciona Díaz (2008):

Desde luego, donde hay vencedores también hay vencidos, y si el discurso evolucionista ha concebido hombres civilizados, modernos, avanzados, históricos y racionales, para ello se ha necesitado su contraparte, ha sido necesario producir al Otro, al vencido por las fuerzas de la naturaleza, al primitivo, salvaje o bárbaro, al tradicional, rezagado, ahistórico e irracional. Sin duda alguna, es sobre la máquina binaria propia de la modernidad donde debemos localizar la condición de posibilidad de una "raza degenerada". La producción del Otro como cuerpo degenerado fue pues necesaria para la producción de "nuestro" hombre moderno: sano, fuerte, vigoroso, trabajador, en suma, útil. El evolucionismo en tanto que dispositivo discursivo, es el acontecimiento neurálgico en la estrategia racial en la medida que permitió una nueva valoración de las fuerzas del cuerpo, una moralización del cuerpo (individual y social) que opera sobre la distinción útil/inútil; el cuerpo bueno es equivalente al cuerpo útil (moderno), como contraparte, un cuerpo malo no es otra cosa que un cuerpo inútil (degenerado). (p. 63)

A pesar de la importancia que dio al país la política modernizadora ${ }^{2}$, las expectativas del hombre moderno se esfumaron, los estereotipos de hombres, mujeres, niños y niñas, se normalizaron y homogenizaron en un patrón humano que no podía cumplirse, en un país principalmente rural señalado de ser una raza inferior y además sin el saber, el conocimiento y la técnica que exige el hombre moderno. Pasamos a ser un país clasificado como subdesarrollado, incapaz de cumplir con los parámetros modernos, como lo menciona Díaz (2008, p. 66) "se configuró el espacio salvaje o lo no-moderno" los no-europeos, ¿los "anormales"?

El hecho de ser clasificados como subdesarrollados nos incluyó en las escalas inferiores del sistema/mundo moderno, haciendo que legitimáramos el orden binario, esta verdad constituida, es una verdad sobre la que hemos sido educados: lo bueno-lo malo, útilinútil, trabajador-holgazán, ignorante-ilustrado, racional-irracional, primitivo-moderno,

\footnotetext{
1. Profesor de filosofía en la Universidad Javeriana (Bogotá, Colombia). Ha publicado varios libros y artículos sobre filosofía social, pensamiento latinoamericano y estudios culturales en América latina

2. Los procesos de modernización o modernizadores consisten fundamentalmente en que los Estados constituidos se ubiquen en la lógica de la economía-política como gran discurso abarcador de toda la realidad. Esta forma de modernidad o de racionalización hace que los Estados ingresen casi como forma natural de la mano del capitalismo industrial en procesos de adecuación de sus estructuras y de sus políticas, para lograr por un lado compararseconlosEstadosensuorden másexitosoyqueapuestentodala estructuratantosocialcomopolíticaenbuscarestameta.(Pulido,2018,p.55)
} 
razas-superiores, razas-inferiores, normal-anormal; términos que pesan en el inconsciente colectivo, una herencia cultural que va definiendo formas de ser, de constituirnos como sujetos. Nos relacionamos a partir de este orden, afirmando las clases sociales establecidas, reconociendo y marcando las jerarquías desde las instituciones, un juego que se normaliza, en el que actuamos permanentemente. Estrategias de biopoder que nos hacen actuar dentro de una estructura del sistema/mundo moderno sin ser calificados como modernos.

El término "anormal" a pesar de ser poco usado actualmente, es necesario revisarlo en su historia para comprender el presente. En este trabajo se tomará como una categoría de la que no se habla abiertamente pero que existe y hace parte de las prácticas discursivas ${ }^{3}$ que señalan socialmente a los sujetos.

En este sentido cabe preguntarse por la educación de "anormales", en los espacios institucionales y la responsabilidad en la constitución de sujetos. Una mirada histórica que permite ver cómo se articulan las fuerzas, cómo son utilizadas por el poder. Los orígenes de la idea de "anormalidad" que la genealogía puede obtener en los discursos de la educación colombiana, y porqué se generan propuestas excluyentes-incluyentes. Además, comprender el lugar de las emergencias de las propuestas educativas y la naturaleza de ellas, su relación con el proyecto de modernización del país y las políticas liberales que se convierten en fundamentos que respaldan verdades para hablar de anormales con palabras nuevas, sofismas distractores de una realidad que permanece en las instituciones. Las relaciones de poder-saber presentes en los discursos, con la influencia e imposición de organismos internacionales (Mejía, 2015).

\section{Metodología}

Tomar la historia como instrumento, desde el enfoque arqueológico-genealógico, es encontrarse utilizando la caja de herramientas de la obra de Foucault (Droit, 2006; Foucault, 1982, 1999), que nos proporciona formas de organización de la información para poner en marcha el pensamiento, hacer un mapa de las ideas, buscar puntos de encuentro entre teorías, problematizar lo que se piensa, en este caso los discursos institucionales respecto a la "anormalidad" que surgen en un momento histórico caracterizado por unos emergentes ideales nacionalistas que crean polémica entre los partidos tradicionales y la iglesia, intentan construir nación desde sus intereses, con miradas opuestas, conservadoras y liberales pero a la vez, acuerdan un lugar importante para la educación, como dispositivo que prepara la masa poblacional para el beneficio de la actividad económica y social.

Trabajar desde el enfoque arqueológico - genealógico requiere, además, sumergirse en los saberes y las prácticas en este caso institucionales, usando instrumentos para indagar en el pasado y tratar de comprender el presente, anotaré que se trata de asumir en palabras de Foucault: la voluntad de saber, que implica tener apertura frente a los acontecimientos, cuestionando las certezas, revisando nuestras relaciones con la verdad. La arqueología analiza la forma y las condiciones en que emerge un acontecimiento, haciendo un análisis crítico de las formaciones históricas, las fuerzas que lo constituyen como saber-poder

\footnotetext{
3. Foucault plantea como prácticas discursivas, los sistemas de acción habitados por el pensamiento de carácter sistemático en una relación de saber, poder y ética y constituye una experiencia o pensamiento. (Castro 2018)
} 


\section{Momentos de la investigación}

El estudio se realizó en dos momentos principales, los cuales no se entienden de manera gradual u ordenada; se permite el tránsito simultaneo, la discusión y retorno a cada instancia.

\section{Consolidación del corpus documental}

El momento corresponde a la selección de las fuentes documentales, en las cuales se incluye leyes, decretos, ordenanzas, resoluciones y acuerdos del campo educativo, publicados entre 1920 y 1970. Si bien la investigación propone un análisis entre los años 40 y 70, fue preciso considerar años anteriores por cuanto algunas normas permanecieron vigentes. Además, se seleccionaron revistas de medicina, revistas de educación y revistas de derecho, catálogo de revistas de la biblioteca Central de la Universidad Pedagógica y Tecnológica de Colombia (UPTC), Biblioteca Patiño Rosselli y red cultural del Banco de la República.

En la primera selección se encontraron 65 documentos correspondientes a normatividad (leyes, decretos, resoluciones), 14 documentos públicos, 23 revistas y 2 cartillas. Al llegar a este punto, se eligen los documentos más pertinentes para realizar las lecturas temática, discursiva, metodológica y crítica.

\section{Tratamiento del archivo}

El trabajo con los documentos permitió la consolidación del archivo, el cual desde la perspectiva foucaultina está comprendido por los enunciados o temáticas centrales, desde los cuales se describen las fuerzas discursivas de la anormalidad en Colombia.

A cada uno de los documentos se le realizó cuatro tipos de lectura a saber: lectura temática, la cual permite la caracterización de las componentes discursivas; lectura discursiva, con la cual se busca establecer relaciones axiales y jerárquicas entre la categorías del discurso; lectura metodológica con la cual se buscan reconocer las condiciones que hicieron posible la consolidación o surgimiento de una categoría; finalmente con la lectura crítica se analiza el funcionamiento ideológico propio del discurso (Zuluaga, 1999).

Cada una de las lecturas estuvo atravesada por dos categorías de análisis principales: la gubernamentalidad, con la cual se pretendió analizar los procesos de modernización en las instituciones, los discursos y las prácticas utilizadas; y la colonialidad/decolonialidad, con el fin de mirar el lugar del sujeto en el contexto colombiano, de acuerdo con los discursos hegemónicos que lo clasifican.

\section{Resultados}

\section{Modelos de poder social}

Las imágenes de la modernidad que llegaban a Colombia por diferentes medios, fueron creando y transformando mentalidades, estilos de vida que prometían entrar en el círculo de una sociedad para un mejor vivir, este no sería exclusivo de las clases dominantes, estaba relacionado con satisfacer necesidades básicas que dan sensación de bienestar y cumplimiento de los propios deseos, además de estar respaldados por estudios científicos, vendiendo de esta forma la idea de progreso.

Los procesos de modernización en Colombia, implicaron una nueva idea de nación: 
La nación pensada, como una "comunidad imaginada" de iguales. Esta idea de unificación ha sido muy poderosa, [...] Las naciones aparecen entre nosotros como objetos o conjuntos culturales limitados, particulares y autocontenidos, precisamente porque son poderosas construcciones simbólicas que ordenan y se sustentan en formas de identificación colectiva e individual. (Castro-Gómez, 2008, p.20)

La nueva organización desde la unidad crea una imagen de homogeneidad y a la vez de normalización de las relaciones entre las personas pertenecientes al grupo social que se identifican con: lengua, tradiciones, raza, pero además, es importante mencionar que los procesos de modernización no llegan solos se requiere poner en marcha estructuras que ayuden al país a encaminarse por la ruta de la industrialización, nuevas formas de producción y por lo tanto hombres preparados para asumir el reto de ser económicamente útiles.

El paso del siglo XIX al XX estuvo acompañado de formas de organización a través de estructuras de la modernidad, las instituciones, como representación del poder social, de una dinámica que genera interacción y la forma de hacer explícito el marco normativo, como lo menciona Klein (2018), el poder social de las instituciones se refleja en la capacidad de articulación de las relaciones de fuerza que se establecen, evidenciándose en los símbolos que dan identidad al ser ciudadano, sensación de estar "amparado" por leyes adecuadas y por formar parte de una construcción social ocupada por instituciones justas y soberanas.

Las instituciones además organizan el tiempo, el espacio, el reconocimiento del otro, determinan el pasado y el porvenir, el ingreso a un grupo social según condiciones, requerimientos, ideales comunes, identificación, intercambio, aclarando que no solo inciden en aspectos sociales del individuo sino repercuten en la vida psiquica y construcción de subjetividad. El Estado como institución mayor genera las relaciones entre todas las demás instituciones: familia, escuela, trabajo y a la vez, cada una de ellas, regula las relaciones entre los individuos. Sin embargo, el neoliberalismo cambia la perspectiva de Estado, relegándolo para destacar la figura del mercado, de esta forma las instituciones se van disgregando, poco a poco dejan de cumplir la función de continuidad y regulación, produciendo integrantes en lugar de ciudadanos.

La institucionalización a comienzos del siglo XX en Colombia, determinó la formación de sistemas educativos públicos, y con ellos la instauración de un sistema de instrucción ${ }^{4}$ como propuesta educativa, además del control y regulación de las acciones de niños y maestros. La disciplina constituyó el medio de adaptación al sistema, disciplina entendida como "fuerza de severidad" que convertía en hábito la norma, así que quienes no cumplen, son excluidos, considerados "anormales", la exigencia consiste en apostar todo lo necesario para el "progreso de los niños" quienes a su vez representarían el progreso de la nación.

La institución se presenta siempre como un sistema organizado de medios. En ello reside, por otra parte, la diferencia entre la institución y la ley: ésta última limita las acciones, aquella es un modelo positivo de acción. [...] toda institución impone a nuestro cuerpo, incluso en sus estructuras involuntarias, una serie de modelos, y confiere a nuestra inteligencia un saber,

\footnotetext{
4. El decreto 491 de 1904 reglamenta la Ley 89 de 1903 de la instrucción pública en Colombia, a través de las secretarías de cada departamento, reglamenta la instrucción e inspección en las instituciones primaria, secundaria y las facultades, articulando servicios como las bibliotecas, museos y observatorio astronómico. Se considera importante también definir funciones para quienes conforman dichas instituciones, se implantan planes de estudio y se definen los requerimientos en cuanto a espacios y materiales que se deben utilizar.
} 
una posibilidad de previsión en forma de proyecto. Llegamos así a esta conclusión: el hombre no tiene instintos, construye instituciones. (Deleuze, 2005, p. 28)

La articulación entre las leyes del estado, las normas impuestas, y la disciplina, en las instituciones, son fuerzas que legitiman modelos sociales. El decreto de instrucción publica define funciones que indican una organización jerárquica: el director del establecimiento que obedece la reglamentación de las Secretarías de Educación y esta vigilado por un inspector, hace que sus maestros cumplan sus funciones, apliquen los planenes de estudio diseñados previamente a sus alumnos, indicándoles además como comportarse en espacios con requerimientos específicos, todas estas fuerzas van conformando un discurso de lo socialmente aceptado; comportamientos, lenguajes, rituales religiosos donde participa el buen cristiano, rituales en el manejo de tiempos y espacios, hora de trabajo hora de descanso, momentos de la clase, lugar que cada uno ocupa y control de su cuerpo.

\section{Instituciones Educativas}

Las instituciones educativas en Colombia se organizan bajo el control de una institución aún mayor, el Ministerio de Instrucción Pública y Salubridad, que luego recibe el nombre de Ministerio de Educación Nacional, (MEN) a partir de la Ley 56 de 1927, ${ }^{5}$ además se determinan funciones de forma específica: la Dirección Nacional de Higiene, la Dirección Nacional de Lazaretos y el Ministerio de Educación Nacional. La técnica principal de la Dirección Nacional de Higiene (Ley 8 de1927, Ley 27 de 1927) consistirá en crear laboratorios de higiene en las capitales de departamento para el control de las enfermedades contagiosas de la población y verificación de la salud de los ciudadanos.

La necesidad de estar vigilantes frente a una enfermedad que afecta a gran parte de la población, se resuelve creando instituciones con acciones que se encarguen de atenderla, es la forma como se articulan distintas formas de poder: la ciencia determina quién tiene la enfermedad, el estado crea las instituciones para su confinamiento, los responsables de estas instituciones establecen normas para cumplir con lo establecido y a la vez hacer que otros cumplan estableciendo una disciplina. Se ejerce un disciplinamiento del cuerpo, el cual debe permanecer en un lugar aislado, además, se apartan los que no están enfermos pero que han adquirido una condición anormal, como los niños que se han quedado sin padres que respondan por ellos, por esto tambíen se les aisla, por cuanto las condiciones de unos y otros ponen en peligro el orden establecido. La credibilidad en el orden que dan las instituciones fortalece la idea de protección respaldada por la norma y a la vez por la sociedad.

La organización de las instituciones no se queda simplemente con la instrucción sobre los modelos de preparación e instrucciones a seguir, sino que, cuenta con disposiciones varias (capítulo XV), sobre el sistema de vigilancia más allá de la escuela, dando participación a la policía para un control más efectivo, ${ }^{6}$ se hace evidente la necesidad de vigilar el cumplimiento de las normas como una obligación, la iglesia y el Estado se complementan, la primera a partir de las creencias plantea los valores como guía educativa que orienta a los sujetos sobre

\footnotetext{
5. Ley 56 de 1927. Art. $1^{\circ}$. Desde el 1º de enero de 1928 el Ministerio de Instrucción y Salubridad Públicas se llamará Ministerio de Educación Nacional. Las funciones relativas a Lazaretos quedan adscritas a la Dirección Nacional de Lazaretos y las relativas a salubridad e higiene quedan adscritas a la Dirección Nacional de Higiene y Asistencia Públicas.

6. Art. 101. Es deber de los alcaldes poner a disposición de los maestros de escuela un Agente ó Comisario de policía que anote los nombres de los niños que cometan faltas fuera de la escuela, para que le dé cuenta al Maestro. El mismo agente tiene la obligación de avisar en las casas que los niños no han concurrido á la escuela, a fin de remediar la falta.
} 
el bien y el mal, el sistema político dispone lo que es conveniente para la República, y a través de las instituciones organiza los tiempos, y los procedimientos de normalización que imponen límites y fijan modelos sociales.

Por lo anterior, es evidente que la educación se impregna del sistema político constituyéndose una biopolítica que a la vez que define al sujeto, trae consigo la posibilidad de expandirse a toda la población, haciendo ver la educación como la mejor posibilidad para ingresar al sistema, fortalecerlo y construir la idea de nación. Sin embargo, el sistema siempre tendrá fisuras por donde escapan los "anormales" dado que no son prioridad en la organización del sistema.

Es a partir de los años 40 que los organismos internacionales como la ONU y la UNESCO, van transformando nuestras instituciones que intentaban seguir la idea de un nacionalismo orientado por el gobierno, ahora, Colombia como miembro de la UNESCO en 1947 entra en el proceso global de masificación de los individuos, en esto juega papel importante el sistema de estadísticas que permite ver índices de natalidad, mortalidad, situación económica, demográfica, analfabetismo, gastos del MEN, promedio nivel de productividad, nivel social, porcentaje de "anormalidades" de la población. Las cifras y estadísticas se convierten en la base para que el sistema educativo implante la técnica de planeación, instrumento principal de acceso masivo a la población, que facilitó la aplicación de tecnologías de instrucción, siguiendo los requerimientos de los organismos internacionales: ONU, UNESCO, BID, OEI, UNICEF, Banco Mundial, entre otros.

Se desarrollan proyectos apoyados por expertos de la UNESCO institución internacional. En la segunda conferencia general realizada en México en 1947, en el capítulo 3 referido a la educación, se destaca como proyectos prioritarios para América Latina: la Educación Fundamental, la Educación de Adultos, el mejoramiento de los materiales de enseñanza y las Misiones consultivas sobre Educación para los Estados Miembros que la soliciten. Todo un plan estratégico que pretendía la extensión de la escuela primaria, desarrollada especialmente en el sector rural. De esta forma se articulan las fuerzas nacionales con las instituciones hegémonicas internacionales, el gobierno colombiano acepta la jeraruía impuesta internacionalmente hallando la razón en la ciencia y la tecnología.

\section{La eugenesia en las instituciones}

El control de la población encaminado a la idea de progreso, también generó estrategias de salud e higiene como una de las prioridades, confiando en el surgimiento de una nueva raza de hombres preparados para asumir el camino a la modernidad y el progreso. La ciencia representada en las disciplinas como: medicina, psicología, psiquiatría, sociología y antropología se ocupa de esta discusión, psicólogos y psiquiatras como Miguel Jiménez López, Luis López de Mesa y Rafael Bernal Jiménez entre otros, presentan teorías que alertan sobre una posible degeneración de la raza de la población colombiana.

[...] se ha hablado de las condiciones de la atmósfera enrarecida de los climas de altura, de su escasa presión, de su menor riqueza en oxígeno, de la cantidad mayor de ácido carbónico que

\footnotetext{
7. UNESCO. Acta de la Conferencia General. Segunda Reunión. México, 1947. Cap 3 Educación. 3.4.1. Que estimule a los Estados Miembros al cumplimiento de las obligaciones que implica el establecimiento de un mínimo de Educación Fundamental para sus respectivos pueblos, de conformidad con el espíritu del artículo 1, párrafo 2 (b) dela Constitución dela Unesco; obligaciones entrelas que figura el establecimiento, en el plazo más breve posible, de una enseñanza primaria general, gratuita y obligatoria, así como el de una educación esencial mínima para los adultos (...)
} 
encierra. Todas esas condiciones, en efecto, son propias para disminuir de manera permanente la actividad nutritiva de los organismos de los sujetos a su influencia e intervienen, al menos en gran parte, en la producción del fenómeno de nuestra regresión vital (Jiménez, 1920, p. 34)

Los estudios de Jiménez López muestran la influencia de la época, el interés por la herencia y la evolución de la especie humana, políticas de higiene racial que se instalaron en el mundo con el propósito de mejorar la especie humana y promover la salud del pueblo, pero a la vez propiciaron la segregación racial y discriminación de las diferencias. En Colombia se buscaron las causas en primer lugar por las condiciones geográficas que justificaban no solo problemas en algunas personas, sino, el riesgo de toda una población que habita el país al estar sometida a unas condiciones geográficas y climáticas.

Obran en el mismo sentido la alimentación ordinaria de nuestro pueblo, escasa en elementos proteicos; la falta permanente de higiene en la mayor parte de la población, lo que debilita los órganos y vicia su funcionamiento desde la primera edad; la inobservancia de los preceptos primordiales de aseo, de baños, de lucha contra los parásitos ordinarios; el sedentarismo de las clases acomodadas; la fatiga corporal de las clases populares; la educación, que en sus procedimientos tradicionales debilita el cuerpo, fatiga el cerebro y aniquila la voluntad; las intoxicaciones alimenticias con sus productos averiados [...], las innumerables afecciones parasitarias y micósicas de la zona tórrida, conocidas unas, las más por estudiar aún; las diversas infecciones que, sin ser peculiares a nuestra latitud, han hallado en ella un campo abierto a su acción devastadora: sífilis, tuberculosis, afecciones tíficas y paratíficas, etc.; la miseria, en fin, con todas sus consecuencias físicas y morales....son otros tantos factores que se integran para engendrar el lamentable e innegable fenómeno de la degeneración de nuestra raza Jimenez, (Jimenez,1920, p.34)

Además de las condiciones ambientales se justifica el deterioro racial por las costumbres, los alimentos, las malas condiciones higiénicas que Jiménez considera determinantes para creer que la raza se degenera incluso con el riesgo de desaparecer. De esta forma es posible considerar que se vive un momento en que el pueblo colombiano en su mayoría está considerado como "anormal" frente a los patrones científicos de la época. Como parte de la solución se consideró urgente estudiar una higiene tropical y de las alturas, señalar la alimentación más conveniente para las diferentes regiones según el clima, pero sobre todo, implantar con legisladores y educadores medidas de higiene pública.

Revisión completa del plan educacional de nuestro país, de modo de dar a la cultura física toda su importancia desde la primera edad; de evitar la fatiga escolar y de formar al educando -en uno y otro sexo- una voluntad firme y personal. Punto es este de importancia incalculable para nuestro porvenir moral. (Jimenez,1920, p.37)

Se ponen en juego como elementos poco favorables: en primer lugar la zona del trópico en la que está ubicado el país, luego la herencia, en consecuencia, es urgente tratar este problema desde las instituciones especialmente educativas, revisando aspectos como: la alimentación, políticas sanitarias y el control de la inmigración, expuestas en la ley 48 de 1920, reformada por la ley 103 de 1927, donde se declara la exclusión a quienes padezcan enfermedades graves, también a los locos, alcohólicos, degenerados, epilépticos, idiotas, cretinos, vagos y mendigos. Propone también la aplicación de técnicas eugenésicas para purificar la raza y reparar el problema de la herencia. (Martínez, 2016) 
Los discursos eugenistas en la primera mitad del siglo XX, son determinantes para el funcionamiento de las instituciones, se atiende a los planteamientos de la medicina que señalan lo normal y lo patológico, a la vez, genera planes correctivos que puedan regenerar la raza mediante estrategias aplicadas en la escuela. La ley 39 de $1903^{8}$ establece las condiciones de funcionamiento de las instituciones, una forma de mantener la vigilancia no solo en espacios y tiempos sino en patrones de vida generadores de sujetos, que viven, piensan y actuan de una determinada manera. En 1948 se crea el departamento de Coordinación de Higiene como dependencia de los ministerios de Educación y Ministerio de Higiene que tiene como objeto organizar la educación higiénica en todo el país, orientando a las instituciones escolares en cuanto a construcción de edificaciones y manejo de restaurantes escolares ${ }^{9}$

Las medidas de carácter sanitario continuaron por la década de los cincuenta haciendo énfasis en la población, es así que las instituciones educativas oficiales y privadas no podían matricular niños que no presentaran su carné de salud. Esta disposición estableció un requerimiento más para ir a la escuela,$^{10}$ las reglas que impone el conocimiento científico, en este caso la medicina indica los requisitos para vivir en comunidad. El lugar que va ocupando la salud en la educación lleva a la revista Cultura ${ }^{11}$ a publicar un artículo especial para el magisterio boyacense titulado "Escuela Nutricional", un manual ${ }^{12}$ de educación nutricional que toma como punto de partida un país donde la pobreza nutricional es evidente, demostrada por las investigaciones del Instituto Nacional de Nutrición, agrega que la gente desconoce sus necesidades nutricionales, atendiendo a la asistencia técnica del doctor Willard A. Krehl, ${ }^{13}$ consultor nutricional, quien demuestra que los maestros en Colombia no están preparados para orientar una conducta higiénica de acuerdo con las experiencias de los niños. Esto demuestra un interés por establecer modelos de nutrición internacional en las escuelas y la familia.

Se espera que el maestro siga las instrucciones puestas en el manual, y sea además un profesor de nutrición, de esta forma entender y propiciar el crecimiento y la evolución normal de los niños, el saber sobre nutrición implicó aprender a definir los límites entre normal y “anormal”, el éxito del programa dependía del maestro, de su práctica de enseñanza, allí podría hacer una selección no solo de nutrición sino de los alumnos con un proceso de desarrollo normal o "anormal".

\footnotetext{
8. Art.41. Todo establecimiento official o particular, tenga o no internado, estará sometido a la inspección del Gobierno en lo tocante al Sistema de alimentación, vigilancia de los dormitorios y demás condiciones esenciales relativas al desarrollo físico y moral de los alumnos. El Ministerio de Instrucción Pública, consultada la Junta de Higiene, dictará las prescripciones del caso.

Exceptúase de esta disposición las congregaciones docentes de religiosos que observen clausura, y cuya inspección corresponde al Ordinario eclesiástico.

9. Decreto 986 de 1948 art. $4^{\circ}$. El Departamento de Coordinación de Higiene, elaborará los programas requeridos para la estrecha colaboración entre los Ministerios de Higiene y Educación, programas que han de contener los puntos básicos para el respectivo proyecto de ley, en la próxima legislatura.

10. Decreto 2234 de 1952. Art. $2^{\circ}$ El carnet [...] será expedido por la autoridad sanitaria competente y en él debe constar que el estudiante es apto para vivir en comunidad y que ha sido vacunado o revacunado contra la viruela y la tifoidea. Los alumnos que ingresen por primera vez a las escuelas primarias deben presentar también constancia de haber sido vacunados contra la tos ferina y difteria. Donde haya servicios de radioscopia o de radiografía se adicionará el carnet con los exámenes pulmonares correspondientes.

11. Revista autorizada a nivel nacional para hacer publicaciones con temas referentes a la educación en Colombia. Revista №107 de 1958

12. El manual está compuesto de cinco títulos: 1. Nutrición e Higiene, 2. Necesidad de educación nutricional, 3. La responsabilidad de la escuela, 4. Por qué el educador necesita preparación nutricional y 5. Objetivos de la educación nutricional

13. Sub- director del Instituto de Investigaciones Nutricionales de la Universidad de Yale, Estados Unidos, quien visitó a Colombia en 1952
} como consultor nutricional del Servicio Cooperativo Inter-Americano de Salud Pública 


\section{Instituciones para "Anormales"}

La categoría "anormal" en Colombia aparece en relación con los discursos eugenistas, la preocupación por la degeneración de la raza por parte de la medicina, la mirada psicologista de la población que utiliza las pruebas para clasificar y la instrucción obligatoria que propone el Estado como medida política que garantice un orden social. Tal perspectiva fundamentada en la razón y la ciencia legitima formas de poder que establecen patrones de normalidad y a la vez reclaman nuevas formas de organización, nuevos discursos educativos que marcan la diferencia entre normal y "anormal".

En la década de los treinta el congreso de Colombia mediante disposiciones legales (Ley 24 de 1931, Ley 54 de 1931, Ley 93 de 1938) determina recursos para la creación de instituciones públicas para ciegos, sordomudos, orfanatos, escuelas de artes y oficios, secciones de policía colonizadora, e internados de indígenas en el Amazonas, Caquetá y Putumayo, orientados principalmente por misiones católicas. Esta institucionalización hace que los sujetos no representen un peligro para la sociedad, en tanto que el Estado se hace cargo y en adelante pueda librar a la sociedad del peligro y desorden de la población marginal como parte del bienestar público.

Por otra parte, el Ministerio de Trabajo Higiene y Previsión Social, (Decreto 2448 de 1936) organizado en secciones y departamentos de asistencia social, así: ingeniería sanitaria, obras de asistencia social, sección de preescolar, escolares, infancia abandonada, niños enfermos y anormales, eugenesia, maternidad y primera infancia, da una mirada distinta sobre los menesterosos que podrían verse como mano de obra disponible, trabajadores que pueden producir al servicio de la nación. Para esto se requiere unas condiciones de salud mínimas que van de la mano con las condiciones higiénicas, todo esto como parte del control y previsión de enfermedades, de la pobreza y el desorden social, base para el progreso de una sociedad y carta de entrada a la modernidad apostándole a tener una población saludable y posiblemente productiva.

Estas instituciones de carácter asistencial, denominadas de "utilidad común" por cuanto destinan un patrimonio a una determinada finalidad social sin ánimo de lucro deben ser vigiladas, y solicitarán aprobación para la inversión de capitales al Ministerio de Gobierno. Este a su vez solicitará concepto previo favorable del Departamento Nacional de Higiene o del MEN o el Departamento de Trabajo según se requiera, si las instituciones son privadas, o se organizan por un acto administrativo del poder público y reciben auxilios del tesoro nacional, estarán sujetas a inspección y vigilancia del gobierno, de igual manera para la Cruz Roja y la Beneficencia. Pero si son las comunidades de orden religioso quienes están a cargo, no están sujetas a estas disposiciones a menos que reciban auxilios del Estado. Esta alianza entre el Estado y las comunidades religiosas fortalece el poder sobre la población, la organización racional y jerárquica.

Sanchez (2014) refiere que el partido liberal apoyado por los conservadores, proponen un proyecto de beneficencia como parte de la caridad cristiana, La constitución de 1886 le dio el nombre de "Beneficencia Pública" a las funciones que el Estado desempeña en relación con enfermos y desvalidos, estas su vez, pueden fundar instituciones adscritas al Estado encargadas de la asistencia social. Las comunidades religiosas encargadas de la administración, comenzaron su labor identificando y caracterizando a los sujetos, luego, 
determinaron el tipo de intervención que debía realizarse, todo esto soportado principalmente en la pedagogía y el conocimiento médico.

La primera institución de Beneficencia que se creó en Colombia fue la del Estado Soberano de Cundinamarca. Empezó sus labores de asistencia en tres frentes: hospicios de niños expósitos, asilos de mendigos, niños desamparados, locas y locos y el Hospital San juan de Dios. [...] fundó tres establecimientos para abordar la problemática de la niñez huérfana y desamparada: el Hospicio, el Asilo de niños y el Asilo de niñas desamparadas. Aunque el Asilo San José fue creado en 1882, la Junta General de beneficencia cambió su denominación por el Asilo de Niños Desamparados en el año 1913 (Sánchez, 2014, p.68)

Además de crear la Beneficencia, en 1934 con la ley 54 el Gobierno crea, organiza y subsidia orfanatos e internados para indígenas en la Intendencia del Amazonas y las Comisarías del Caquetá y el Putumayo. Estos internados estarán a cargo de las Misiones católicas cuyo objeto principal es catequizar la población para acercarla a las creencias religiosas. Por otra parte, en las mismas regiones se crean las escuelas de artes y oficios, esperando además que cultiven la tierra, con derecho a que a las misiones se les adjudique el terreno cultivado, de esta forma las comunidades religiosas no solo imponen la religión, sino territorializan el lugar. Servir al gobierno es una de las indicaciones principales, se confía en la iglesia para la resolución del problema de la pobreza. Los indígenas son vistos como pobres que deben ser auxiliados, domesticados, convertidos a la fe cristiana, la solución se encuentra con la creación de instituciones encargadas de normalizar la población para poder entrar en una escala del círculo social.

La propensión por moralizar la educación desde los principios y la doctrina católica (recristianización de la educación) atendidió a la necesidad de fijar para la educación fines más elevados tratando de alejarla de la confrontación política del momento. Noobstante, este discurso "catolizante" contribuyóa fortalecer imaginarios políticos excluyentes en la medida en que desde la iglesia se emprendió un feroz ataque contra el liberalismo, considerándolo como masón y anticristiano y, por ende, enemigo de la Nación y de los fundamentos que ésta le dieron origen. (Pinilla, 1999, pp. 38-39)

Bajo el precepto de la moralidad el gobierno en su acción educativa apoyada por la iglesia usa las instituciones para la clasificación y el control de la población, según su posibilidad y productividad: instituciones educativas académicas para quienes pueden orientarse a la universidad, instituciones técnicas que orientan a los estudiantes a la vida práctica y el trabajo, instituciones para ciegos y sordomudos, para individuos de esta condción que sean aptos para ser educados, ${ }^{14}$ asilos, casas de menores, orfanatos, para los anormales, quienes deben ser aislados como medida de orden, organización y protección de la ciudadanía, considerando necesario comenzar por las principales ciudades como Bogotá, Cali, Medellín.

La junta central de higiene, creada a partir de la ley 30 de 1886 vigente hasta 1953, y con apoyo del Ministerio de Salud, realiza el control de epidemias. Además, dado su conocimiento científico fue estimada esencial la asistencia a las instituciones de beneficencia, en la solución

14. Decreto 1421 de 1942. Art. $3^{\circ}$ : La Federación Nacional de Ciegos y Sordomudos recibirá una participación del 15\% del producido de impuestos, de conformidad con el artículo anterior, y el 85\% restante será distribuido por el Ministerio de Trabajo e Higiene y Previsión Social, entre las siguientes entidades: Instituto Colombiano para Ciegos de Bogotá; Escuela de las Hermanas de la Sabiduría, de Bogotá; Escuela de Ciegos y Sordomudos de Medellín, y Escuela de Ciegos y Sordomudos de Cali, en proporción al número de ciegos y sordomudos que atiendan, de matrícula efectiva, y aptos para la educación 
de problemas de pobreza y enfermedades. Confiando en los conocimientos científicos, se considera pertinente también que los médicos intervengan en las construcciones de edificios para hospitales, asilos, casas de salud, dispensarios, manicomios, según lo indicado por la ley 99 de 1922. Esto indica la preocupación del gobierno por dar un lugar destacado a la ciencia y a la razón, lo inteligible, racionalizando el espacio, la arquitectura, dando la apariencia de orden, donde se pueden anticipar y predecir los acontecimientos.

En el panorama nacional, a partir de 1946 trabajan como entidades separadas el Ministerio de Educación Nacional y el Ministerio de Salud Pública, con gran influencia de las organizaciones internacionales especialmente norteamericana en el tema de salud toma los lineamientos técnicos del Servicio Cooperativo Interamericano de la Salud pública (SCISP) y con éste se adihere a las Convenciones Sanitarias Internacionales.

La organización sanitaria en Colombia creada con una intención económica disfrazada de filantrópia a comienzos del siglo XX, se refleja en el tipo de apoyo que reciben las instituciones en los departamentos. El problema está visto desde la productividad, por lo tanto, quienes no generan ingresos deben esperar.

\section{Conclusiones}

Pertenecer a un grupo social, a una escuela en particular, no solo revela una aceptación, sino tener acceso a la verdad establecida. Quienes quedan por fuera de los grupos sociales, no tienen verdades validadas socialmente, son señalados como un grupo al margen, un nuevo grupo que carece de verdades en el sentido de no ser capaces de construirlas, por el contrario, las verdades que pesan sobre ellos las construyen los normales, y las convierten en técnicas de domesticación y corrección, de esta forma se genera la idea de que tratar al "anormal," requiere un nivel más elaborado de corrección, por lo tanto un sistema de vigilancia más agudo, como el que pueden desarrollar los padres en un espacio mas estrecho y familiar así el individuo deja de ser el hijo, el hermano, para convertirse en el individuo universalmente reconocido por su anomalía. La generalización que se realiza según la caracterización de la ciencia, hace que se olvide el individuo en su particularidad, se le someta a la mirada homogenizante que lo ubica en un lugar, socialmente determinado, ejerciendo un control para garantizar el funcionamiento del sistema, a pesar de esto, el monstruo, el "anormal" es quién resulta cuestionando los sistemas por no encajar en ellos.

La influencia que ha tenido la ciencia desde las disciplinas: la biología, la psicologia, la antropologia, la autoriza para definir un comportamento "anormal" que alerta las instituciones, pero también someten el sujeto a la normalidad desde sus planteamientos, la mejor forma de hacerlo es el sistema educativo, organizando la manera de ver la escuela, analizando comportamientos que caracterizan las acciones humanas, a través de las relaciones que se establecen en la cotidianidad de maestros y alumnos, las prácticas escolares establecidas desde la normalidad, pueden generar estereotipos simplificadores de la realidad incapaces de dar el valor a cada niño o niña y a la forma como el contexto puede afectar de manera particular su ser interior y exterior.

Por otra parte, para los "anormales" vistos también como sujetos, deben pertenecer a instituciones, con diferentes propósitos; pasan del encierro y aislamiento a comienzos del 
siglo XX, al estudio y clasificación en la segunda mitad del mismo siglo; con la aparición de la psicología, los nuevos procedimientos que le dan el calificativo de menor, carente de... esto genera una actitud de toma de distancia para señalar al extraño que por serlo debe ser caracterizado y estudiado; creándose instituciones para retrasados mentales, para ciegos, para sordos, programas para campesinos, hospicios para pobres, cárceles para menores infractores, deja de ser el ser individual y se marca su diferencia.

Cuando el Estado crea instituciones no solo normaliza, sino que señala y objetiviza a quienes salen de la norma, dando mayor crédito a los estudios especializados sobrela anomalía, en educación, medicina, psicología y psiquiatría y otros más. Estudios especializados que en lugar de acercarnos a la situación que viven estas personas, en su aislamiento los sentimos extraños, porque deben ser tratados desde un lenguaje exclusivo de la ciencia, garantizando la continuidad del sistema que establece una verdad a costa de quienes no son comprendidos ni atendidos desde su forma particular de existencia. Hablar de "anormales" implica tomar en cuenta al sujeto transformado en objeto por una sociedad que clasifica para justificar sus falencias, señalando la anormalidad: como necesidades educativas especiales, discapacidades, o personas objeto de inclusión.

La categoría de gubernamentalidad permite pensar la educación de anormales en relación con la modernización en el periodo 1940-1970, puesto que el gobierno colombiano junto con los organismos internacionales, establecen relaciones de fuerza a las que se unen las instituciones, éstas aunque tengan carácter asistencial o educativo, tienen un mismo mecanismo de poder: ciencia, iglesia, estado y se aplican por medio de: planes, programas proyectos, estrategias de cómo abordar poblaciones salvajes, ignorantes o perezosas que estarían en los renglones más bajos de la evolución.

\section{Referencias}

Castro, E. (2018). Diccionario Foucault: Temas, Conceptos y Autores. Argentina: Siglo XXI Editores

Castro-Gómez, S. (2007). ¿Disciplinar o poblar? La intelectualidad colombiana frente a la biopolítica (1904-1934). Nómadas, 26, 44-47.

Castro-Gómez, Santiago, \& Grosfoguel, R. (2007). El giro decolonial: Reflexiones para una diversidad epistémica más allá del capitalismo global. Siglo del Hombre Editores.

Castro-Gómez, Santiago, \& Restrepo, E. (2008). Genealogías de la colombianidad: Formaciones discursivas y tecnologías de gobierno en los siglos XIX y XX. Edtitorial Pontificia Universidad Javeriana.

Decreto 491. Diario Oficial de Colombia 12122-12123, 14,15 de julio (1904).

Decreto 2448. Diario Oficial de Colombia 23321, 30 de octubre (1936).

Decreto 986. Diario Oficial de Colombia 27009, 07 abril (1948).

Decreto 2234. Diario Oficial de Colombia 28051, 13 de noviembre (1952).

Deleuze, G. (2005). La Isla Desierta y otros textos. Valencia: Pretextos 
Díaz, D. (2008). Raza, pueblo y pobres: Las tres estrategias biopolíticas del siglo XX en Colombia (1873-1962). En S. Castro-Gómez \& E. Restrepo, Genealogías de la colombianidad: Formaciones discursivas y tecnologías de gobierno en los siglos XIX y XX. Edtitorial Pontificia Universidad Javeriana.

Droit, R. P. (2006). Entrevistas con Michel Foucault. Ediciones Paidós.

Echeverria, R. (1958). Escuela Nutricional. Revista Cultura. Hemeroteca UPTC [107]

Foucault, M. (1982). Las palabras y las cosas: Una arqueología de las ciencias humanas. Siglo XXI.

Foucault, M. (1999). Arqueología del saber. Siglo XXI.

Foucault, M. (1982). Las palabras y las cosas: Una arqueología de las ciencias humanas. Siglo XXI.

Jiménez, M. (1920). Nuestras Razas Decaen: Algunos signos de degeneración colectiva en Colombia y en los países similares. Cartagena: Memoria presentada al Tercer Congreso Médico Colombiano. Bogotá. Imprenta y litografía de Juan Casis

Ley 39. Diario Oficial de Colombia 11,931, 30 de octubre (1903)

Ley 8. Diario Oficial de Colombia 20587, 6 de septiembre (1927).

Ley 27. Diario Oficial de Colombia 20621, 13 de octubre (1927).

Ley 56. Diario Oficial de Colombia 20645, 15 de noviembre (1927).

Ley 24. Diario Oficial de Colombia 21619, 17 de febrero (1931).

Ley 54. Diario Oficial de Colombia 21676, 29 de abril (1931).

Ley 93. Diario Oficial de Colombia 23923, 15 de noviembre (1938).

Ley 99. Diario Oficial de Colombia 18657, 16 de diciembre (1992).

Martínez, A. (2016). La degeneración de la raza. Bogotá: Scripto S:A:S.

Mejía, M. (2015). La educación popular en el siglo XXI. Una resistencia intercultural desde el sur y desde abajo. Praxis \& Saber, 6(12), 97 - 128. https://doi.org/10.19053/22160159.3765

Pinilla, A. (1999). Educación y cultura política: un balance historiográfico del periodo 19461953. Revista Colombiana De Educación, (38-39).https://doi.org/10.17227/01203916.5433

Pulido, O. (2018). La Universidad como Proyecto Modernizador: Ilusiones y desencantos. Editorial UPTC

Sánchez, J. (2014). Los hospicios y asilos de la Beneficencia de Cundinamarca entre 19171928: discursos y prácticas. Sociedad y economía, (26),65-92

UNESCO (1947). Acta de la Conferencia General. Segunda Reunión. México, 1947. Cap $3^{\circ}$ Educación. 3.4.1

Zuluaga, O. (1999). Pedagogía e Historia. La historicidad de la pedagogía. La enseñanza, un objeto de saber. Editorial Universidad de Antioquia - ANTHROPOS - Siglo del Hombre Editores. 